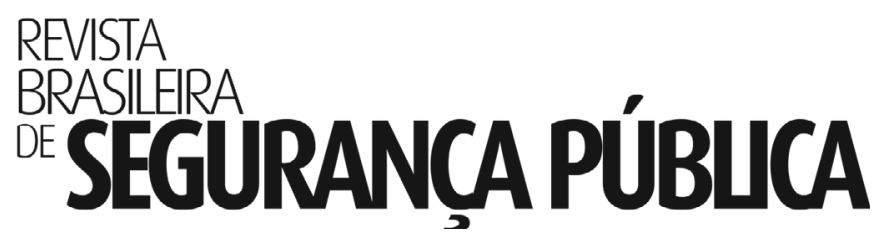

\author{
Volume 12 \\ Número 2 \\ Agosto/Setembro de 2018
}

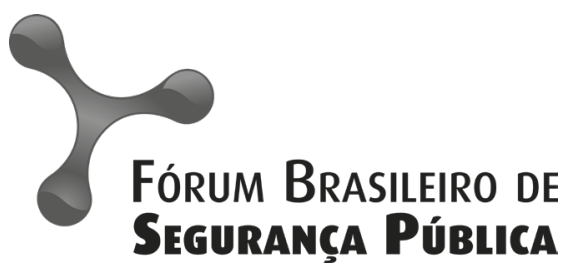

ISSN 1981-1659 


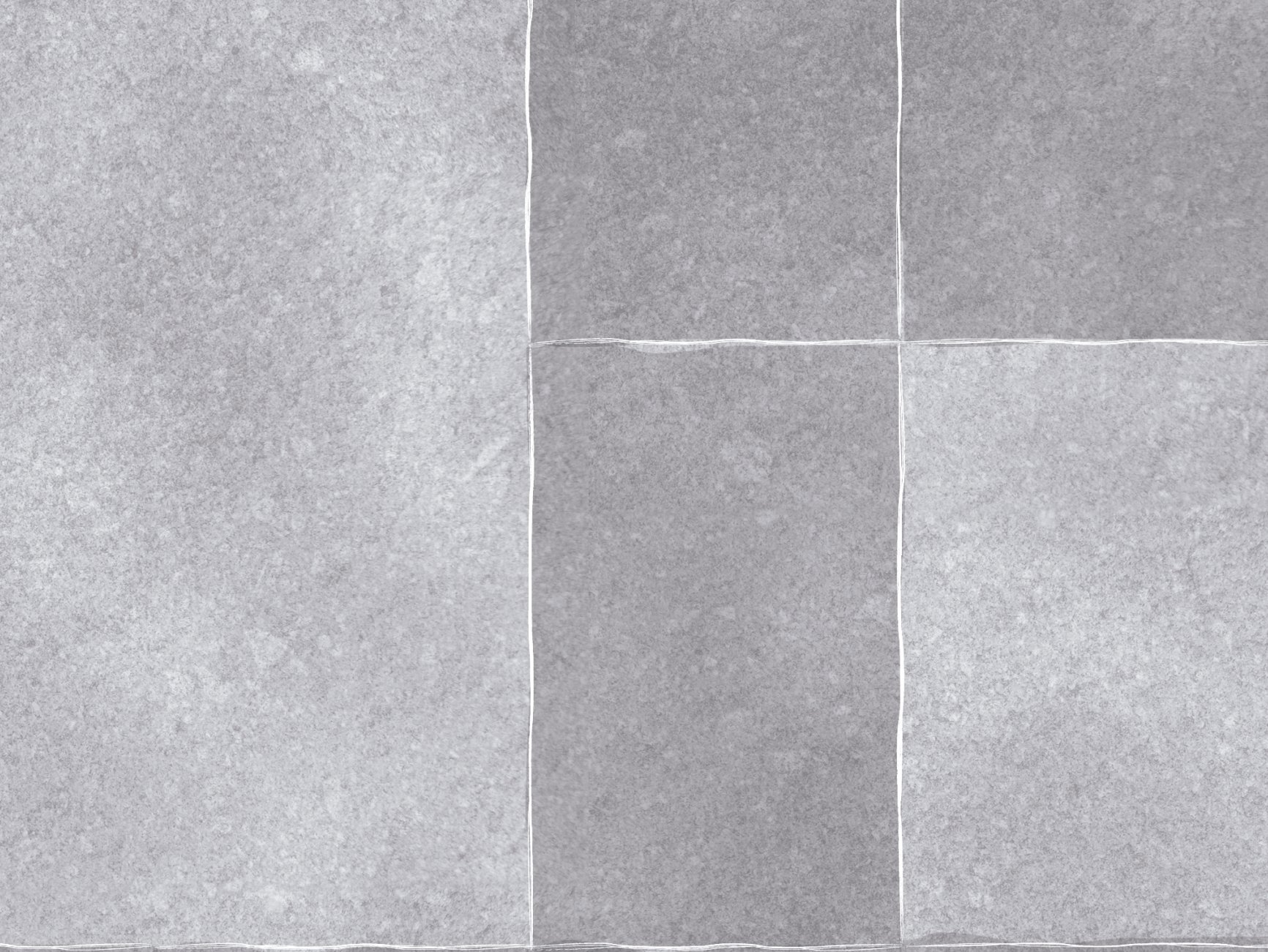




\section{Impactos do Acesso à Informação So- bre as Percepções de Adolescentes Acerca da Violência Doméstica e Fami- liar Contra as Mulheres}

\section{Yara Lopes Singulano}

Mestra em Economia Doméstica pela Universidade Federal de Viçosa, advogada e professora do curso de Direito da Faculdade Governador Ozonam Coelho, em Ubá-MG.

\section{Karla Maria Damiano Teixeira}

PhD em Ecologia Fomiliar pela Michigan State University, Estodos Unidos. É Professora Associado do Departamento de Economia Doméstica da Universidade Federal de Viçoso, Pesquisadora 2 do CNPq, e líder do grupo certificado de pesquisa do CNPq "Famílios, Políticas e Gênero".

Data de recebimento: 19/06/2018

Data de aprovação: 16/11/2018

DOI: $10.31060 /$ rbsp.2018.v12.n2.959

\section{Resumo}

o presente trabalho objetivou analisar em que medido o acesso à informação poderia impactar a percepção de adolescentes sobre o fenômeno da violência doméstica e familiar contra os mulheres, partindo-se da premissa de que ações educativas são eficientes para promover a prevenção desse tipo de violêncio. Para tonto, buscou-se, especificamente, ouferir a opinião dos participantes a priori, bem como posteriormente à realização de uma oficina pedagógica, comparando-se seus posicionamentos nesses dois momentos. Sete adolescentes, alunos de uma escola pública do interior de Minos Gerais, foram entrevistados e responderam, ainda, a um questionório em escala do tipo Likert, e suas respostas foram analisadas através do método de análise de conteúdo (Bardin, 2011). Os resultodos apontaram que ações pontuais que promovam o acesso à informação, como oficinas e palestras, têm sua eficácia limitada para alterar as percepções dos participantes; ou sejo, sõo insuficientes para fomentar uma onálise crítico acerco dos modelos sociais hegemônicos, como o organização patriarcal da família e a divisão sexual de tarefas, e sobre o próprio fenômeno da violêncio doméstica e familiar. Nesse sentido, pode-se concluir pela necessidade de inclusõo das discussões sobre questões de gênero no cotidiano escolar, através de políticas públicas educacionais que contemplassem toda a trajetória escolar dos indivíduos. Além disso, ficou evidenciado que o discurso midiático exerce uma influência significativa sobre a percepção dos adolescentes, tornando-se indispensável sensibilizar a mídia sobre o problema da violência de gênero, para que adote uma abordagem nõo-sexisto e nõo-violento.

Palavras - Chave

Violêncio doméstica e familiar contro as mulheres; Acesso ò informação; Educação em direitos humanos; Adolescentes. 


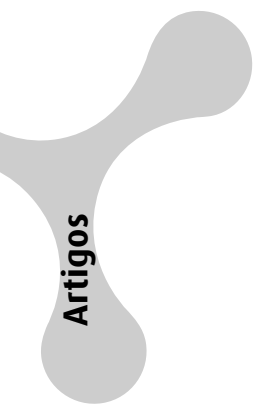

\section{Abstract \\ Impacts of the Access To Information on the Perceptions of Adolescents on Domestic and Family Violence Against Women}

The present study aimed to analyse the extent to which occess to information could affect the perception of adolescents on the phenomenon of domestic and family violence against women, starting from the premise that educational actions are efficient to promote the prevention of this type of violence. In order to do so, it sought specifically to reach out for the opinion of the participants a priori, as well as after a pedagogical workshop, comparing their positions in these two moments. Seven adolescents, from a public school in the interior of Minas Gerais were interviewed and also answered a Likert-type questionnaire, and their answers were analysed using the content analysis method (Bardin, 2011). The results pointed out that punctual actions that promote access to information, such as workshops and lectures, have limited effectiveness in altering participants' perceptions; that is, they are insufficient to foster a critical analysis of hegemonic social models such as the patriarchal family organization and the sexual division of tosks and the very phenomenon of domestic and family violence. In this sense, one can conclude that there is the need to include the discussions on gender issues in the daily school life, through public educational policies that contemplate the entire school trajectory of individuals. Moreover, it showed that the media discourse exerts a significant influence on the adolescents' perception, making it necessary to sensitize the media about the problem of gender violence, so that it adopts a non-sexist and non-violent approach.

\section{Keywords}

Domestic and family violence against women; Access to information; Human rights education; Adolescents. 


\section{INTRODUÇÃO}

A violência contra as mulheres, cuja manifestação mais comum é a violência doméstica e familiar, é uma verdadeira epidemia global, resultado de estruturas sociais patriarcais e androcêntricas que fomentam a desigualdade de gênero e o machismo (RITT; CAGLIARI; COSTA, 2009; PASINATO, 2016). A violência doméstica e familiar contra as mulheres emerge como uma tentativa masculina de controle e dominação, quando as mulheres se insurgem contra os papeis sociais que tradicionalmente lhes são destinados (CABRAL, 1999; SEQUEIRA; STELLA, 2012).

A violência intrafamiliar geralmente se configura como uma tentativa masculina de resoluçáo de conflitos, alimentada por uma cultura de violência que permeou todo o processo de formaçáo da sociedade brasileira (SEQUEIRA; STELLA, 2012). Assim, diante da rebeldia ou insubordinaçáo feminina, a violência, enquanto forma de correção do comportamento considerado desviante, é socialmente justificada, e naturalizada; enquanto a agressividade masculina é tolerada e, até mesmo, incentivada (RITT; CAGLIARI; COSTA, 2009). A violência doméstica e familiar é um fenômeno complexo, fruto da com- binação de diversas características, tanto sociais quanto econômicas, psicológicas e culturais, que se manifestam a nível pessoal ou coletivo (ALVES, 2005). Nenhum desses fatores age sozinho; trata-se da interação de diversas condiçóes. Alguns fatores de risco indicam maior probabilidade para a ocorrência de violência em âmbito doméstico ou familiar, como baixo nível de escolaridade, falta de acesso à informaçáo, pobreza, abuso de álcool e outras drogas, ter presenciado ou sofrido violência na infância, circunstâncias estas que potencializam o conflito (CABRAL, 1999; OMS, 2012).

Devido a essa complexidade, o mero enfrentamento criminal do problema não é suficiente, sendo necessária a adoção de novas abordagens pelas políticas públicas que pretendam erradicar essa forma de violência (CAMPOS, 2017).

Nesse sentido, as ações de cunho preventivo têm-se mostrado eficientes (OMS, 2012; CAMPOS, 2017). Embora já previstas pela Lei 11.340/2006 - Lei Maria da Penha, no âmbito do tratamento integral da violência, as açóes preventivas ainda não implementadas de forma sistemática pelo Estado brasileiro (PASINATO, 2015). Dentre elas, políticas públicas edu- 
cacionais que promovam o acesso à informação são as mais importantes, visto que podem ser capazes de promover mudanças nas estruturas socioculturais que sustentam a violência de gênero (CABRAL, 1999; ALVES, 2005). Indica-se, ainda, que tais açóes sejam voltadas, com maior ênfase, às faixas etárias mais jovens, como crianças e adolescentes, visando a prevenção primária da violência (OMS, 2012).

Outrossim, o objetivo da pesquisa foi analisar em que medida o acesso à informação pode impactar a percepção de adolescentes sobre o fenômeno da violência doméstica e familiar contra as mulheres. Para tanto, como objetivos específicos buscou-se auferir a opinião dos participantes sobre a violência doméstica e familiar contra as mulheres, a priori; depois, foi realizada uma oficina pedagógica sobre o tema com os participantes; e, após a realizaçáo dessa atividade, foram coletadas novamente as opinióes dos adolescentes, para serem comparadas.

Como técnica para coleta de dados, utilizou-se uma entrevista baseada em roteiro semiestruturado, e um questionário em escala do tipo Likert. A metodologia utilizada para a análise das respostas dos participantes foi a análise de conteúdo, conforme proposta por Bardin (2011).

\section{Abordagem Metodológica}

Essa é uma pesquisa do tipo exploratório-descritiva-analítica. Foi realizada em uma escola pública estadual de um município do interior de Minas Gerais, com menos de 20 mil habitantes, e cuja maior parte da população é rural (IBGE, 2016). A opção por esse local foi motivada por duas tendências que vêm sendo apontadas no que tange à violência homicida no Brasil: a disseminação e a interiorização, que se constituem no aumento das taxas de homicídios em regióes não-metropolitanas e fora das capitais, em um processo de reorganização da violência no território nacional (WAISELFISZ, 2011; ANDRADE; DINIZ, 2013). Além disso, os estudos sobre violência doméstica e familiar no Brasil ainda são realizados, majoritariamente, nos grandes centros urbanos, especialmente no eixo Rio-São Paulo (SEQUEIRA; STELLA, 2012); não obstante, dados apontam que os municípios de pequeno porte são os que apresentam maiores índices de homicídio de mulheres, conforme evidencia Waiselfisz (2015), uma peculiaridade que ainda não pode ser explicada, e merece atenção, justificando a realização de pesquisas em municípios com esse perfil.

A amostra dessa pesquisa foi composta por sete adolescentes, alunos do ensino médio, sendo quatro do gênero feminino e três do gênero masculino; uma aluna do $1^{\circ}$ ano, quatro alunos do $2^{\circ}$ ano, e dois alunos do $3^{\circ}$ ano. Desses sete, apenas uma participante era moradora da zona urbana. Para a coleta de dados, utilizou-se um questionário $^{1}$ e uma entrevista baseada em roteiro semiestruturado, aplicados em dois momentos distintos, para comparaçáo dos resultados: a primeira aplicação, sem que os participantes tivessem recebido

10 questionário foi construído com inspiração na pesquiso "Tolerância social à violência contro a mulher" (IPEA, 2014), que utilizou escala do tipo Likert de 5 pontos no questionário aplicado aos participantes: discorda totalmente; discorda parcialmente; neutro; concorda parcialmente; concorda totalmente. 
qualquer informação prévia por parte da pesquisadora a respeito desse tipo de violência, para verificar o seu conhecimento $a$ priori sobre o tema; e a segunda aplicação, uma semana após a realizaçáo de uma oficina pedagógica com os participantes, para verificar se houve mudança nas respostas.

A oficina realizada com os participantes foi elaborada pela pesquisadora com $\mathrm{o}$ intuito de apresentar-lhes a violência doméstica e familiar contra as mulheres enquanto violência de gênero, motivada e fomentada por uma estrutura social sexista e patriarcal. Buscou-se enfatizar a gravidade do problema que a violência doméstica e familiar representa, e como essa prática está arraigada na cultura brasileira. Assim, procurou-se, também, discutir com os adolescentes o problema da desigualdade de gênero, além da naturalizaçáo da violência nos relacionamentos familiares e afetivos. Também foram abordados os principais pontos relativos à aplicaçáo da Lei Maria da Penha, explicando alguns direitos previstos na lei, como a questão das medidas protetivas de urgência, ressaltando-se, ainda, a importância dessa legislação para a sociedade, enquanto norma voltada a proteger os direitos humanos das mulheres.

A oficina foi realizada na própria escola, com duraçáo de 100 (cem) minutos, e foram utilizadas metodologias ativas. Os alunos sentaram-se em círculo com a pesquisadora, que primeiro exibiu o curta-metragem "Acorda Raimundo... acorda!" (ACORDA, 1990), para iniciar os debates acerca dos papeis desempenhados por homens e mulheres em nossa sociedade. Também foram utilizadas charges para fomentar os debates sobre a posiçáo de subalternidade feminina, e apresentadas manchetes de jornal para que os alunos refletissem sobre a dimensão do problema que é a violência doméstica e familiar contra as mulheres no Brasil. Foi dado espaço para que os adolescentes compartilhassem suas próprias vivências, tornando a oficina dinâmica e o debate mais próximo de sua realidade.

Quanto à análise dos questionários e das entrevistas, as respostas dos participantes foram submetidas à análise de conteúdo, seguindo metodologia proposta por Bardin (2011). Assim, foi realizada uma pré-análise dos textos, visando a organização e sistematizaçáo das informaçóes; em seguida, foi realizada a codificação, agrupando as redaçóes em unidades de registro, e a categorização semântica (por tema), seguindo o sistema de grade mista; passando, entáo, à análise propriamente dita, via inferência e interpretação.

\section{Fundamentação Teórica}

Desde o advento da Lei Maria da Penha, em 2006, o enfrentamento da violência doméstica e familiar contra as mulheres no Brasil assumiu novos contornos, alterando-se profundamente o tratamento jurídico dado à questão, bem como as diretrizes para criação de políticas públicas atinentes ao tema. Novas diretrizes para a criação de políticas públicas também foram previstas no texto legal, a fim de promover uma abordagem integral da violência, multi e transdisciplinar (CAMPOS, 2017). Não obstante, passados onze anos da promulgaçáo da Lei, o que se vislumbra é a implementação parcial de seus mecanismos, o que compromete a sua eficiência em coibir a violência doméstica e familiar contra as mulheres (PASINATO, 2015). 
O Estado brasileiro vem priorizando políticas públicas criminais no enfrentamento à questão, e políticas preventivas, em especial, não foram implementadas em massa (CAMPOS, 2017).

Medidas educativas, quando destinadas a crianças e adolescentes, são amplamente recomendadas para promover a prevençáo da violência, mostrando-se especialmente eficientes na promoção da prevenção primária, ou seja, para evitar o primeiro episódio de violência (CABRAL, 1999; OMS, 2012). Nesse sentido, destaca-se que a Lei Maria da Penha prevê que "a política pública que visa coibir a violência doméstica e familiar contra a mulher far-se-á por meio de um conjunto articulado de ações da União, dos Estados, do Distrito Federal e dos Municípios e de açóes não-governamentais, tendo por diretrizes", dentre outras, "a promoção e a realização de campanhas educativas de prevençáo da violência doméstica e familiar contra a mulher, voltadas ao público escolar e à sociedade em geral, e a difusão desta Lei e dos instrumentos de proteção aos direitos humanos das mulheres", bem como "a promoção de programas educacionais que disseminem valores éticos de irrestrito respeito à dignidade da pessoa humana com a perspectiva de gênero e de raça ou etnia" (BRASIL, 2006, art. 8ㅇ, incisos V e VIII). Não obstante, a discussão sobre questóes de gênero e direitos humanos das mulheres não foi integrada ao currículo escolar brasileiro, sem previsão correspondente na Lei de Diretrizes e Bases da Educação Nacional ou na Base Nacional Comum Curricular, restando inócua, por enquanto, tal previsão normativa (MELLO, 2010).

Frisa-se, ainda, que o Brasil assumiu internacionalmente, ao aderir ao Plano de Ação do Programa para Educação em Direitos Humanos da Organização das Nações Unidas - ONU, o compromisso de promover políticas públicas voltadas à promoção da educação em direitos humanos, entendida esta como "um conjunto de atividades de educação, de capacitação e de difusáo de informaçáo, orientadas para criar uma cultura universal de direitos humanos" (UNESCO; ACNUDH, 2006, p. 01). Nacionalmente, foi elaborado o Plano Nacional de Educaçáo em Direitos Humanos - PNEDH, segundo o qual a educação em direitos humanos deve ser "um dos eixos fundamentais da educaçáo básica e permear o currículo, a formaçáo inicial e continuada dos profissionais da educação, o projeto político-pedagógico da escola, os materiais didático-pedagógicos [...]" (BRASIL, 2007, p. 32), sendo citada pelo documento a promoçáo da igualdade de gênero como um dos objetivos balizadores do PNEDH.

Importante mencionar, ainda, a Resoluçáo no 01 , de 30 de maio de 2012, do Ministério da Educação, que estabelece Diretrizes Nacionais para a Educação em Direitos Humanos, a qual define:

Art. $5^{\circ}$ A Educaçáo em Direitos Humanos tem como objetivo central a formaçáo para a vida e para a convivência, no exercício cotidiano dos $\mathrm{Di}$ reitos Humanos como forma de vida e de organizaçáo social, política, econômica e cultural nos níveis regionais, nacionais e planetário.

$\$ 1^{\circ}$ Este objetivo deverá orientar os sistemas de ensino e suas instituiçóes no que se refere ao planejamento e ao desenvolvimento de açóes de Educação em Direitos Humanos adequadas às 
necessidades, às características biopsicossociais e culturais dos diferentes sujeitos e seus contextos.

$\$ 2^{\circ}$ Os Conselhos deEducação definirão estratégias de acompanhamento das açóes de Educação em Direitos Humanos.

Art. $6^{\circ}$ A Educaçáo em Direitos Humanos, de modo transversal, deverá ser considerada na construçâo dos Projetos Político-Pedagógicos (PPP); dos Regimentos Escolares; dos Planos de Desenvolvimento Institucionais (PDI); dos Programas Pedagógicos de Curso (PPC) das Instituiçóes de Educação Superior; dos materiais didáticos e pedagógicos; do modelo de ensino, pesquisa e extensão; de gestão, bem como dos diferentes processos de avaliação. (BRASIL, 2012)

Tais normas vão de encontro ao cada entendimento, cada vez mais consolidado internacionalmente, de que a educação em direitos humanos, visando o respeito à dignidade humana e à igualdade, é meio eficaz para a prevençáo de conflitos e de violência, incluindo a violência de gênero (UNESCO; ACNUDH, 2006; BRASIL, 2007). O acesso à informaçáo pode fomentar mudanças socioculturais significativas, ao permitir a desconstruçáo de mitos e estereótipos sobre a violência doméstica e familiar contra as mulheres. Ao considerar a violência doméstica e familiar como uma violação aos direitos humanos, assume-se que esse é um problema público, cuja erradicação é responsabilidade de todos (CABRAL, 1999; ONU MULHERES, 2015). Além disso, o acesso à informação é imprescindível para o exercício efetivo dos direitos das mulheres em situação de violência e para o seu empoderamento (MUSSI; COSTA, 2014; UNICEF, 2015). Em contrapartida, estudos indicam que a falta de acesso à informação é um fator de risco para a ocorrência de violência (SEQUEIRA; STELLA, 2012).

\section{Resultados e disscussão}

Inicialmente, buscou-se apreender, através da aplicação do questionário e da entrevista, as opinióes que os participantes detinham, a priori, sobre questóes diretamente relacionadas à violência doméstica e familiar contra as mulheres e à Lei Maria da Penha, e também ao modelo patriarcal de organizaçáo familiar e ao desempenho de papeis de gênero. Depois da realização da oficina pedagógica, cuja função foi de promover o acesso dos participantes à informaçáo, tanto o questionário quanto a entrevista foram reaplicadas, e as respostas dadas nos dois momentos, comparadas.

\section{0 modelo patriarcal de organização fa- miliar e papeis de gênero}

Buscou-se verificar as opiniōes dos adolescentes a respeito de questóes envolvendo o modelo patriarcal de organização familiar e ao exercício de papeis de gênero, visto que essas estruturas sociais sáo responsáveis por fomentar e naturalizar a violência contra as mulheres.

Ao analisar as respostas dos participantes, foi possível verificar que persistia, mesmo após a sua participação na oficina, a adesão a estereótipos sexistas e ao modelo patriarcal de família entre seis deles, como pode ser observado dos trechos a seguir:

Concordo totalmente [que seja normal o homem ficar nervoso ou com raiva por sentir ciúme]. Porque onde não tem ciúmes não tem amor. (1 ${ }^{\circ}$ ano, feminino $)$

Concordo totalmente [que o homem dê a pa- 
lavra final sobre decisões domésticas]. Porque ele tem mais direitos na casa, ele sempre é o chefe, ele tem que ser o dono da casa, eu acho. ( $3^{\circ}$ ano, masculino)

Concordo totalmente [que a mulher deve saber cozinhar e cuidar da casa para ser boa esposa]. Porque se ela quis casar ela sabe desde sempre que ela vai ter que fazer essas coisas para o marido dela. ( $2^{\circ}$ ano, feminino)

Concordo totalmente [que a mulher não deve sair sozinha ou vestir roupas curtas, se isso desagrada seu parceiro]. Porque se ele náo quer que ela saia com aquela roupa ela tem que respeitar né, porque senão pode acontecer alguma coisa grave. Se ela sabe, se ele for ciumento e não gostar, ela tem que respeitar a decisão dele. ( $2^{\circ}$ ano, feminino)

As respostas desses participantes indicaram que eles aquiesciam com padróes de relacionamento pautados na submissão feminina, no exercício de poder pelo homem, e na divisão sexual de tarefas, indicando a permanência do modelo patriarcal como ideal de organizaçáo familiar, bem como a manutençáo de papeis de gênero, entre esses adolescentes. Além disso, verificou-se que tais participantes também corroboravam valores machistas que culpabilizam a mulher pela violência sofrida, quando esta age contrariamente à moral patriarcal. É o que se evidencia com a fala a seguir, por exemplo.

Concordo totalmente [que mulher que usa roupa curta "está pedindo" para ser assediada]. Porque roupa curta chama muita atençăo e a mulher pode ser violentada, pode ser estuprada, ela fica andando na rua e o homem fica olhando, fica mexendo. ( $3^{\circ}$ ano, masculino)

Mesmo após a realização da oficina, na qual foi discutida a questáo da violência sob uma perspectiva de gênero, buscando-se ressaltar as diferenças socialmente construídas entre homens e mulheres, bem como a discriminaçáo contra as mulheres, a maioria dos participantes manteve posiçóes machistas ao responder o questionário. A participaçáo na atividade, portanto, parece não ter sido suficiente para levá-los a uma reflexão crítica sobre o problema da violência doméstica e familiar contra as mulheres, tampouco acerca da desigualdade de gênero e da estrutura social que fomenta a violência. As convicçoóes dos participantes continuaram pautadas, sobretudo, em suas experiências pessoais, como se observa no excerto a seguir.

Concordo totalmente [que em briga de marido e mulher não se mete a colher]. Tenho o exemplo em casa [risos]... acho que não tem que intervir não, em nenhuma hipótese, porque pode dar desentendimento depois. Igual lá em casa, meu tio gostava de beber muito, brigava com minha tia, a gente foi intervir... eles estão juntos até hoje, mas não combinam mais com a familia. ( $3^{\circ}$ ano, masculino)

A violência doméstica e familiar contra mulheres é naturalizada, em razão de valores socioculturais que fomentam a discriminaçáo do gênero feminino e a primazia do masculino. Nesse cenário, torna-se difícil promover uma mudança cultural que vise a equidade entre homens e mulheres, uma vez que a violência e a discriminação muitas vezes sequer são identificadas como tal, quando se manifestam de forma mais sutis (SEQUEIRA; SETELLA, 2009). 
Um passo importante nesse caminho é descontruir estereótipos sexistas que limitam o desenvolvimento das mulheres e promovem a violência, como lembra Bandeira (2014).

A permanência de estereótipos sexistas e de uma cultura de desvalorizaçáo das mulheres impede o alcance da real igualdade de gênero, alcançada apenas formalmente até hoje. Para Essayag (2013), esses valores são a base de legitimação para que agressores exerçam a discriminação e a violência contra as mulheres. Por isso, o fim da violência contra mulheres exige uma mudança sociocultural, que perpassa pela desconstrução dos padróes, hoje hegemônicos, de afetividade e de organização familiar, pautados na divisão sexual do trabalho, na submissão feminina e na autoridade masculina.

Nesse sentido, Córdoba (2006) ressalta a responsabilidade da família, da escola e da mídia na prevençáo à violência, visto serem os principais agentes educadores e formadores de opinião. Todavia, verifica-se, no Brasil, a ausência de discussóes sistemáticas e contundentes sobre as relações de gênero e direitos humanos no currículo escolar (MELLO, 2010). Quanto ao discurso midiático, constata-se que perpetua estereótipos de gênero, e não raro culpabiliza a vítima pela violência sofrida (BLAY, 2003); além disso, discursos punitivistas, não condizentes com o sistema de proteçáo dos direitos humanos, têm se popularizado na mídia brasileira, exigindo do Poder Público açóes de controle, que, todavia, não estão sendo implementadas (VIANNA, 2010; WOJCIECHOWSKI, 2015).
Quanto à questão educacional, um levantamento recente sobre políticas de promoção de igualdade de gênero na educação, envolvendo 32 secretarias de educaçáo estaduais e de capitais brasileiras, apontou que a maioria desenvolve apenas açóes pontuais, como palestras e cursos de capacitaçáo de curto prazo, e sequer possuem orçamento próprio para esse tipo de ação (CARRERA, 2016). Não obstante, ainda segundo referido estudo, o mero acesso à educaçáo formal não é suficiente para promover uma cultura de paz e a equidade de gênero. No mesmo sentido, a pesquisa "Tolerância social à violência contra as mulheres", realizada pelo Instituto de Pesquisa Econômica Aplicada (IPEA, 2014), revelou que a escolaridade não é táo relevante para explicar a tolerância à violência quanto a adesáo a certos valores, apontando que pessoas que tendem a concordar mais com o modelo patriarcal de organização familiar e com estereótipos sexistas são mais propensas a tolerar a violência. $\mathrm{O}$ estudo conclui que "transformar a cultura machista que permite que mulheres sejam mortas por romperem relacionamentos amorosos, ou que sejam espancadas por não satisfazerem seus maridos ou simplesmente por trabalharem fora" (IPEA, 2014, p. 24) é o maior desafio a ser enfrentado atualmente para diminuir os casos de violência doméstica e familiar contra as mulheres.

É preciso considerar que a escola, enquanto instituição, é propensa a reproduzir os padróes hegemônicos vigentes; os documentos que norteiam as políticas educacionais brasileiras ignoram o problema da violência de gênero, como constatou Mello (2010), e, por isso, o currículo 
tradicional não é suficiente para promover essa mudança cultural. Outrossim, mostra-se urgente e necessário revisar o currículo escolar, a fim de implementar políticas educacionais perenes, que abordem de forma sistematizada a questão de gênero sob a perspectiva de respeito aos direitos humanos, para combater a violência doméstica e familiar contra as mulheres (CÓRDOBA, 2006; RODRIGUES; RAMOS; SILVA, 2013).

\section{Violência e Lei Maria da Penha}

Quanto às questóes diretas sobre violência e sobre a Lei Maria da Penha, notou-se que, diante de questóes sobre manifestações explícitas de violência, os participantes apresentavam menor tolerância. Duas afirmações em especial, "homem que bate na esposa ou namorada deve ir para a cadeia" e "a lei Maria da Penha foi um avanço para a sociedade brasileira", tiveram concordância (total ou parcial) de todos os participantes, tanto antes quanto depois da realização da oficina pedagógica.

Não, eu acho que não é exagerado [a preocupação com a violência contra as mulheres] não, porque acontece mesmo, a gente vê, se a gente for abrir jornais, internet mesmo, se a gente vai pesquisar lá, no jornal está tudo, e são agressóes digamos assim monstruosas, porque éhomicídio, é espancamento, eu acho que não é exagerado não. (3o ano, masculino)

Concordo totalmente [que quando há violência a separação do casal é a melhor saída], porque separaçáo, você vai estar separando e vai estar $\mathrm{OK}$. ( $2^{\circ}$ ano, feminino)

Discordo totalmente [que "tapa de amor não dói”], porque dói sim. (1º ano, feminino)
Concordo totalmente [que homem que bate na parceira deve ir para a cadeia], isso é uma covardia. (2o ano, feminino)

Resultados semelhantes foram obtidos pela pesquisa "Violência contra a mulher: o jovem está ligado?", na qual 96\% dos participantes afirmaram aprovar a Lei Maria da Penha e acreditar que existe machismo no Brasil; mas, ao mesmo tempo, boa parte concordava com padróes machistas e reprovava comportamentos não-conservadores das mulheres (INSTITUTO AVON; DATA POPULAR, 2014). No mesmo sentido, a pesquisa "Tolerância social à violência contra mulheres" apontou a aceitaçáo de discurso genérico/abstrato contra a violência pelos participantes, mas revelou a permanência de uma cultura machista e de tolerância a violência, com culpabalização da vítima sobretudo em situaçóes de assédio sexual (IPEA, 2014). Esses resultados apontam que a populaçáo possui apenas um conhecimento superficial acerca do problema, de modo que náo conseguem identificar manifestaçôes mais sutis de violência ou de discriminação (CÓRDOBA, 2006).

Comparando-se especificamente as respostas dos participantes às perguntas realizadas na primeira e na segunda entrevista, relacionadas diretamente à violência e à Lei Maria da Penha, verificou-se mudanças positivas. Essa parte da coleta de dados vislumbrava principalmente determinar o nível de conhecimentos objetivos dos participantes, questionando-os, por exemplo, sobre o significado da expressáo "doméstica e familiar", e se conheciam as medidas protetivas de urgência previstas na Lei Maria da Penha. Embora esse conteúdo tenha sido tratado na oficina, os adoles- 
centes parecem ter tido dificuldades para assimilá-lo. Por fim, não foi observado nenhum padrão na análise por gênero ou série; o que se notou é que as adolescentes participaram mais ativamente da oficina, mas, quanto às respostas ao questionário $\mathrm{e}$ à entrevista, não houve diferença entre os gêneros.

Na primeira entrevista, todos os participantes afirmaram conhecer a existência da Lei Maria da Penha, e que se tratava de uma lei para proteger as mulheres; contudo, desconheciam o conteúdo da lei, a exemplo das medidas protetivas de urgência e dos tipos de violência previstos. $\mathrm{Na}$ segunda entrevista, quando perguntados sobre tais questóes, os participantes pareceram ter dificuldades para se lembrar do que foi visto na oficina, mas, estimulados, conseguiram recuperar essas informaçóes.

Eu lembro de algumas violências, que fala que é violência psicológica... Não, não sabia [que existiam outros tipos de violência]. Para mim era só de você bater na pessoa que era considerado violência, o resto não. ( $2^{\circ}$ ano, feminino)

Ah, que se a mulher denunciar o cara, [ele] tem que manter distância da mulher, que ele não pode mais ficar perto dela e essas coisas. ( $3^{\circ}$ ano, masculino)

Inferiu-se que a unânime opiniáo positiva dos participantes em relaçáo à Lei Maria da Penha, e a maior facilidade em assimilar as informaçóes atinentes ao seu conteúdo, deve-se, em parte, à cobertura midiática sobre a promulgação e aplicação da Lei, que, como ressaltam Bonetti, Pinheiro e Ferreira (2008), desde sua criação tem sido amplamente divulgada pela mídia nacional. Além disso, como destaca Guimarães (2012, p. 119), os participantes podem sentir uma necessidade de responder de forma "politicamente correta" a essas questóes, rechaçando a violência explícita e manifestando concordância com a aplicação da Lei.

$\mathrm{Na}$ primeira entrevista, perguntados sobre porque haveria a necessidade de uma lei só para mulheres, uma participante não soube responder, disse que nunca havia pensado a respeito; quatro participantes acreditavam que era porque as mulheres são "mais frágeis"; e apenas dois disseram que é porque mulheres são discriminadas e sofrem mais violência. A ideia de que mulheres merecem ser protegidas por uma lei específica pois são o "sexo frágil" (expressão usada por um participante do $3^{\circ}$ ano), um estereótipo sexista que limita o papel das mulheres na sociedade, ainda estava presente nas respostas da segunda entrevista.

Sobre medidas para erradicar esse tipo de violência, na primeira entrevista, 06 adolescentes afirmaram que a vítima deve denunciar o agressor; todos mantiveram esse posicionamento na segunda vez em que foram entrevistados.

Eu acho que a vítima passar a denunciar né, porque geralmente a vítima náo denuncia, eu acho que [a soluçăo] está mais nas vítimas mesmo, nelas passarem a denunciar. ( $2^{\circ}$ ano, feminino)

Existe o risco de culpabilizar a mulher em situaçáo de violência quando se atribui a ela a responsabilidade de dar fim às agressóes, por meio da denúncia. $\mathrm{Na}$ oficina, tentou-se mostrar que a denúncia é um direito, e não uma responsabilidade 
da vítima, bem como discutir os motivos que podem levar a mulher a não denunciar, quais sejam: dependência financeira e emocional do agressor, medo de perder os filhos, medo de sofrer alguma represália do agressor, receio do julgamento social. Também buscou-se apresentar a perspectiva de que esse fenômeno é fruto de arranjos sociais que promovem a discriminação das mulheres e a violência como forma de resolução de conflitos. Pelas respostas da maioria dos participantes, entretanto, observou-se que eles não compreenderam essa dimensáo pública do problema, nem o papel da educaçáo na construçáo de uma cultura de equidade de gêneros. Apenas uma participante mencionou açóes educativas para erradicar esse tipo de violência.

Notaram-se também posições punitivistas entre alguns participantes, o que se credita à influência da mídia, que vem popularizando a (falaciosa) ideia de que o direito penal é a solução para problemas sociais (VIANNA, 2010; WOJCIECHOWSKI, 2015), como se observa dos trechos seguintes.

Eu acho que tinha que criar uma lei mais dura, que se o homem batesse na mulher ou coisa assim, dar uma pena maior para ele, falar com ele para não fazer isso mais, falar com ele para acabar com isso porque não é coisa de se fazer com uma mulher, dar uma prensa a mais, acho que é isso. Eu acho que [a Lei Maria da Penha] não é suficiente, porque homem agride a mulher, aí vai lá e fala o que que aconteceu e aí não dá em nada. Eu acho que tinha que ser mais duro, a lei tinha que pegar mais duro com o homem. (3o ano, masculino)

Ah, dar uma sentença de prisão bem grande para não acontecer mais isso [a violência contra mulheres], [para] o cara tomar vergonha na cara. (10 ano, feminino)

A adequada punição dos agressores é um aspecto importante para o combate a esse tipo de violência, um crime invisível contra o qual muito recentemente as vítimas conquistaram a proteção estatal (ROCHA; GONÇALVES; DAROSSI, 2009). Náo obstante, o eficiente enfrentamento da violência doméstica e familiar contra as mulheres exige mais que a execução de políticas criminais, devendo-se conjugar açóes de proteção e prevenção, como destaca Campos (2017). Além disso, em um Estado Democrático de Direito, mesmo as políticas criminais devem ser efetivadas em consonância com os princípios de direitos humanos, ao contrário do discurso de que "bandido bom é bandido morto", que vem se popularizando no Brasil, em grande parte devido à cobertura midiática (WOJCIECHOWSKI, 2015).

Acredita-se que, por tratar de um tema complexo e que remonta a crenças e experiências muito subjetivas dos participantes, além de ter trazido muitas informaçóes com as quais os participantes nunca tinham tido contato, a realizaçáo da oficina teve seu impacto limitado. Os próprios adolescentes, na segunda entrevista, relataram que era "difícil lembrar de tudo” (2o ano, feminino). Náo obstante, perguntados sobre o que acharam da realização da atividade, todos se manifestaram positivamente.

[A oficina foi importante] Para eu entender também a questão da Lei Maria da Penha, porque a gente só escuta falar mas nunca estudamos sobre isso, e a gente estudou a história dela, estudou o 
que que está dentro da lei, igual eu achava que a Lei Maria da Penha era só para agressão física mesmo, que não entravam outras coisas. Essa questão das leis, essa questão da Lei Maria da Penha, dos direitos, do que era [antes da lei], eu fiquei gente, como assim? Eu fiquei boba com essas coisas. E também do percentual [de vítimas]... e eu não sabia que transexual também podia ser considerado né, que entrava dentro da questão da Lei Maria da Penha, não fazia ideia, achei que era só mulher, mulher, mulher, mulher, então muita coisa que eu não sabia, trouxe muita informação. ( $2 \mathrm{o}$ ano, feminino)

Eu achava que a Lei Maria da Penha tratava só de mulheres casadas ou envolvidas em relacionamentos, mas depois da oficina eu pude perceber que a Lei Maria da Penha está em um conjunto com a sociedade inteira, e pode ser usada para qualquer mulher, eu não sabia que mulheres solteiras tinham direito a essa lei. ( $3^{\circ}$ ano, masculino)

Perguntados se conheciam alguma mulher, em sua família ou vizinhança, que sofria esse tipo de violência, cinco participantes responderam positivamente. Esse dado mostra que a violência está próxima desses adolescentes, e que é necessário fornecer-lhes as ferramentas necessárias para realizarem uma análise crítica dessa prática, sob o risco de, náo o fazendo, que eles considerem a violência natural e assimilem esses padróes de comportamento em suas próprias vidas, perpetuando o ciclo da violência (BONETTI; PINHEIRO; FERREIRA, 2008).

A promoção da equidade de gênero e o fim da violência contra as mulheres exigem uma mudança nas estruturas sociais hoje dominantes, patriarcais e sexistas. Todavia, esse processo de mudança exige esforços contínuos e sistemáticos; açóes pontuais, como a realização de palestras e oficinas, parecem náo ser eficientes para promover alteraçóes duradouras e significativa na percepção dos indivíduos. Nessa pesquisa, notou-se que a realização da oficina pedagógica não foi suficiente para se sobrepor às experiências pessoais dos participantes, que mantiveram suas crenças mesmo após terem tido acesso à informação. É preciso problematizar, também, que o currículo escolar não contempla esse tipo de discussão, e que os participantes afirmaram não ter participado de nenhum projeto ou evento em sua escola, ou comunidade, acerca do tema. Portanto, sem acesso à informação através da escola, a mídia é quem assume um importante papel como formadora de opiniáo para esses jovens; e a cobertura midiática, não raro, reafirma estereótipos e tabus sobre a violência (BLAY, 2003; MIRANDA, 2017).

$\mathrm{O}$ acesso à informação para as faixas etárias mais jovens é crucial para fomentar a mudança sociocultural necessária para erradicar a violência doméstica e familiar contra as mulheres. Como lembra Carvalho (2015, p. 239-240), "na cultura patriarcal/androcêntrica a violência é aprendida, legitimada e reproduzida como expressão de masculinidade hegemônica, o jeito de ser homem mais valorizado"; daí a necessidade de reconstruir os padróes de masculinidade, sobre bases de tolerância e respeito. Nesse sentido, promover o acesso à informação para o gênero masculino pode permitir que os homens se tornem conscientes "sobre suas próprias atitudes, valores e comportamentos em relação às mulheres, mudando quando necessário, e garantindo que eles náo se envolvam pes- 
soalmente em nenhuma discriminação ou violência" (ONU MULHERES, 2015, p. 02).

A falta de informaçáo constitui, ainda, impeditivo para o real acesso à justiça por mulheres em situação de violência, como alertam Mussi e Costa (2014). O desconhecimento do que é a violência doméstica e familiar, e de quais são seus direitos, pode impedir não somente que as mulheres busquem os serviços públicos de atendimento para tentar sair da situação de violência, mas até mesmo que percebam estar em um relacionamento abusivo, pois esse tipo de violência é tão naturalizado que muitas de suas manifestaçóes sequer são interpretadas como uma agressão pelas vítimas (SEQUEIRA; SETELLA, 2009). Pesquisas têm apontado que grande parte da populaçáo associa a violência somente a agressôes físicas (CÓRDOBA, 2006; IPEA, 2014), o que permite que uma série de outras violaçóes sejam perpetradas (INSTITUTO AVON; DATA POPULAR, 2014).

Os resultados da pesquisa "Violência contra as mulheres: o jovem está ligado?" (INSTITUTO AVON; DATA POPULAR, 2014), e também os dados obtidos no presente estudo, apontam não somente que a violência está presente nos relacionamentos dos jovens brasileiros, mas também que estes jovens praticam e perpetuam comportamentos abusivos sem se darem conta de que o fazem, uma vez que a violência é naturalizada e tolerada culturalmente. Assim, torna-se necessário também refletir com esses jovens acerca da cultura de violência que permeia os processos de socialização, e, em especial, os relacionamentos familiares e afetivos.
Frisa-se, ainda, que o empoderamento das mulheres é um dos objetivos centrais da Plataforma de Ação de Pequim e um compromisso assumido juridicamente pelo Brasil diante da assinatura de tratados internacionais (FROSSARD, 2006). $\mathrm{O}$ processo de empoderamento perpassa necessariamente pelo acesso à informação, para que, ciente de seus direitos, as mulheres controlem suas próprias histórias e, enquanto classe, busquem soluçóes mais efetivas para o fim da discriminação de gênero (UNICEF, 2015).

Por todo o exposto, entende-se que promover o acesso à informaçáo deve ser um eixo central de açáo estatal para prevenir a violência doméstica e familiar contra as mulheres (CÓRDOBA, 2006). Contudo, é preciso frisar que os resultados dessa pesquisa parecem indicar que açóes pontuais que promovam acesso à informaçáo têm sua eficácia limitada diante da complexidade do tema tratado, indicando a necessidade de uma alteração das próprias políticas públicas educacionais brasileiras para contemplar discussóes sistemáticas e aprofundadas ao longo de toda a trajetória escolar, visando promover a educação das novas geraçóes segundo uma perspectiva de respeito aos direitos humanos, sob os princípios da não-violência, do respeito aos direitos humanos e da igualdade de gênero.

Como bem lembram Rodrigues, Ramos e Silva (2013), é compromisso de um Estado que se diga democrático promover uma educaçáo voltado para o respeito aos direitos humanos. A escola se constitui como espaço privilegiado para a promoçáo de uma cultura de respeito aos direitos 
humanos (BRASIL, 2007), o que torna essencial que se inclua, de modo sistematizado e perene, no currículo escolar brasileiro, a educação em direitos humanos, aí abrangida a questáo da igualdade de gênero e o debate acerca da violência doméstica e familiar contra as mulheres. Conforme parecem apontar os resultados da pesquisa, ações pontuais e esparsas, como as que vem sendo desenvolvidas, de forma isolada e precária, nas escolas brasileiras, não são suficientes para promover a mudança cultural necessária para fomentar o respeito aos direitos humanos das mulheres, e, assim, erradicar a violência contra elas.

Mesmo diante da existência, no ordenamento nacional, de normas que preveem a inclusão da educaçáo em direitos humanos e da questáo de gênero no cotidiano escolar, de forma transversal e sistematizada, como o mencionado Plano Nacional de Educação em Direitos Humanos e a Resoluçáo 01/2012 do Ministério da Educação, além de dispositivos da própria Lei Maria da Penha, não se vislumbra a efetivaçáo dos preceitos normativos. Rodrigues, Ramos e Silva (2013, p. 175) atentam para a "resistência de forças conservadoras no governo", que vêm inibindo a implementaçáo de políticas públicas na seara educacional, sobretudo quando relacionadas aos temas gênero e sexualidade. É preciso superar tais forças e implementar, de forma contundente, políticas públicas educacionais que visem a formação em direitos humanos e a discussão da desigualdade de gênero e sua relação com a violência, através, por exemplo, da inclusão do tema na Base Nacional Comum Curricular, como ressalta Mello (2010).

Também é preciso enfatizar que o dis- curso midiático ainda propaga estereótipos de gênero e tabus sobre a violência doméstica e familiar contra as mulheres, além de um discurso punitivista, que desrespeita os direitos humanos; é preciso sensibilizar a mídia, enquanto importante formadora de opiniáo e disseminadora de informaçóes, sobre o problema da violência de gênero, para que adote uma abordagem não-sexista e náo-violenta (UNESCO; ACNUDH, 2015).

\section{Conclusão}

A pretensão deste trabalho era analisar em que medida o acesso à informação poderia impactar a percepçáo de adolescentes sobre o fenômeno da violência doméstica e familiar contra as mulheres. Devido às peculiaridades da amostra, ressalta-se que os resultados obtidos nesta pesquisa não podem ser generalizados, mas que são apontadas aqui conclusóes corroboradas pela literatura e por outras pesquisas empíricas, e que podem fomentar interessantes debates no futuro.

Os participantes apresentaram, a priori, baixo nível de informaçáo a respeito da violência doméstica e familiar e sobre a Lei Maria da Penha, alta concordância o modelo patriarcal de organizaçáo familiar e com valores sexistas e machistas. Todos manifestaram conhecer a existência da Lei Maria da Penha, mas nenhum tinha conhecimento a respeito do conteúdo da lei, de direitos ou de mecanismos nela previstos.

Após a realizaçáo de uma oficina pedagógica com os participantes, foram novamente entrevistados, para averiguar-se o impacto do acesso à informação em suas respostas. Notou-se que os adolescentes ti- 
veram mais facilidade para assimilar dados objetivos, como os tipos de violência previstos na lei Maria da Penha e o que são as medidas protetivas, embora náo tenham demonstrado mudanças em suas crenças pessoais, continuando a manifestar concordância com valores patriarcais, sexistas e machistas. Associou-se o baixo nível de informação dos adolescentes à ausência de discussóes sistematizadas de temas ligados a direitos humanos e à questão de gênero no currículo escolar brasileiro. Assim, diante da ausência de uma abordagem formal sobre o tema, a percepçáo dos adolescentes ficaria fortemente influenciada pela mídia e por vivências pessoais, resultando em posturas de tolerância à violência e de concordância com valores discriminatórios e machistas.

Concluiu-se ainda que, embora o acesso à informação seja de fundamental importância para promover a prevenção da violência doméstica e familiar contra as mulheres, açóes pontuais e esparsas, como oficinas e palestras, podem ter seu potencial educativo limitado, especialmente no tocante às crenças pessoais dos adolescentes; ou seja, mostraram-se insuficientes para fomentar uma análise crítica acerca dos modelos sociais hegemônicos, como a organização patriarcal da família e a divisão sexual de tarefas.

Portanto, para promover, de fato, a mudança cultural necessária para erradicar a desigualdade de gênero e a violência contra as mulheres, é preciso incluir as discussóes sobre questóes de gênero no cotidiano escolar, através de políticas públicas educacionais perenes, que contemplem toda a trajetória escolar dos indivíduos, inclusive de forma transversal. Nesse sentido, a efetivaçáo das proposiçóes do PNEDH (BRASIL, 2007) e a inclusão da educação em direitos humanos, de forma contundente, na Lei de Diretrizes e Bases da Educação Nacional e na Base Nacional Comum Curricular, mostram-se cruciais.

Além disso, uma vez que ficou evidenciado que o discurso midiático exerce uma influência significativa sobre a percepção dos adolescentes, de modo que se mostra indispensável também sensibilizar a mídia, enquanto importante formadora de opinião e disseminadora de informaçóes, sobre o problema da violência de gênero, para que adote uma abordagem não-sexista e não-violenta.

\section{Referências Bibliográficas}

ACORDA, Raimundo... Acorda! Direção de Alfredo Alves. Produção de Ceta-ibase. Rio de Janeiro, 1990. (16 min.), son., color. Disponível em: <https://www.youtube.com/watch?v=JIN8ujwOTeE>. Acesso em: 10 nov. 2018.

ALVES, Cláudia. Violência doméstica. Faculdade de Economia da Universidade de Coimbra. Coimbra, 2005. Disponível em <http://www4.fe.uc.pt/fontes/trabaIhos/2004010.pdf>. Acesso em: 14 mai. 2018.
ANDRADE, Luciana Teixeira de; DINIZ, Alexandre Magno Alves. A reorganização espacial dos homicídios no Brasil e a tese da interiorização. Revista Brasileira de Estudos de População, São Paulo, v. 30, 2013, supl. p. S171-S191.

BARDIN, Laurence. Análise de conteúdo. Ed. rev e ampl. São Paulo: Edições 70, 2011. 
BANDEIRA, Lourdes Maria. Violência de gênero: a construção de um campo teórico e de investigação. Sociedade e Estado, Brasília, v. 29, п. 2, mai./ago. 2014, p. 449-469.

BLAY, Eva Alterman. Violência contra a mulher e políticas públicas. Estudos Avançados, São Paulo, v. 17, n. 49, set./dez. 2003, p. 87-98.

BONETTI, Aline; PINHEIRO, Luana; FERREIRA, Pedro. Violência contra as mulheres e direitos humanos no Brasil: uma abordagem a partir do Ligue 180. In: XVI Encontro Nacional de Estudos Populacionais, 2008, Caxambu-MG. Anais eletrônicos... Disponível em: <http://www. abep.org.br/publicacoes/index.php/anais/article/ view/1740>. Acesso em: 14 mai. 2018.

BRASIL. Comitê Nacional de Educação em Direitos Humanos. Plano Nacional de Educação em Direitos Humanos. Brasilia: Secretaria Especial dosDireitos Humanos, 2007. 76 p. Disponível em: <http://portal.mec. gov.br/index.php?option=com_docman\&view=downloadgalias=2191-plano-nacional-pdf 8 |temid=30192 > . Acesso em: 15 dez. 2018.

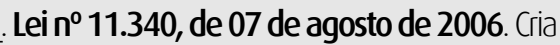
mecanismos para coibir a violência doméstica e familiar contra a mulher, nos termos do $\S 80$ do art. 226 da Constituição Federal, da Convenção sobre a Eliminação de Todas as Formas de Discriminação contra as Mulheres e da Convenção Interamericana para Prevenir, Punir e Erradicar a Violência contra a Mulher; dispõe sobre a criação dos Juizados de Violência Doméstica e Familiar contra a Mulher; altera o Código de Processo Penal, o Código Penal e a Lei de Execução Penal; e dá outras providências. Disponível em: <http://www.planalto.gov. br/ccivil_03/_ato2004-2006/2006/lei/l11340.htm>. Acesso em: 14 mai. 2018.

. Ministério da Educação. Conselho Nacional de Educação. Conselho Pleno. Resolução nº 01, de 30 de maio de 2012. Estabelece Diretrizes Nacionais para a Educação em Direitos Humanos. Diário Oficial da União: Braślila, 31 de maio de 2012. Seção 1. p. 48.

CABRAL, Maria Aparecida Alves. Prevenção da violência conjugal contra a mulher. Ciência e Saúde Coletiva, Rio de Janeiro, vol. 4, n. 1, 1999, p. 183-191.

CAMPOS, Carmen Hein de. Lei Maria da Penha: necessidade de um novo giro paradigmático. Revista Brasileira de Segurança Pública, São Paulo, v. 11, n. 1, fev./ mar. 2017, p. 10-22.

CARRERA, Denise (coord.). Gênero e educação: fortalecendo uma agenda para as políticas educacionais. São Paulo: Ação Educativa, Cladem, Ecos, Geledés, Fundação Carlos Chagas. 2016. 248 p. Disponível em: <http://generoeeducacao.org.br/wp-content/uploads/2016/12/generoeducacao_site_completo.pdfs. Acesso em: 14 mai. 2018.

CARVALHO, Maria Eulina P. de. Relações de gênero e violências na escola: da compreensão à superação. In: BRABO, Tânia Suely Antonelli Marcelino (Org.). Mulheres, gênero e violência. Marilia: Oficina Universitária, São Paulo: Cultura Acadêmica, 2015, p. 225-246.

CÓRDOBA, Cristina Pintor et al. Violencia doméstica contra la mujer: visión desde la adolescencia. Revista Clínica de Medicina de Familia, Albacete, Espanha, v. 1, n. 3, fev. 2006, p.115-120.

ESSAYAG, Sebastián. El compromiso de los Estados: planes y políticas para erradicar la violencia contra las mujeres en América Latina y el Caribe. PNUD; ONU Mujeres, Panamá, out. 2013. 79 p.

FROSSARD, Heloísa (org.). Instrumentos Internacionais de Direitos das Mulheres. Brasilia: Secretaria Especial de Políticas para as Mulheres, 2006. 260p. Disponível em: <http://www.observatoriodegenero.gov. br/menu/publicacoes/outros-artigos-e-publicacoes/ instrumentos-internacionais-de-direitos-das-mulheres/ view >. Acesso em: 05 out. 2017.

GUIMARÃES, Marina Oliveira. Direito e gênero: a percepção da violência contra a mulher e da Lei Maria da Penha na comarca de Ponte Nova/Minas Gerais. 2012. 135 p. Dissertação (Mestrado em Economia Doméstica). Universidade Federal de Viçosa, Viçosa-MG. 
IBGE - INSTITUTO BRASILEIRO DE GEOGRAFIA E ESTATístICA. Resultado IBGE Cidades 2016. Disponível em: < https://cidades.ibge.gov.br/brasil/mg/ervalia/pesquisa/13/5902 >. Acesso em: 18 out. 2017.

INSTITUTO AVON; DATA POPULAR. Violência contra a mulher: o jovem está ligado? 2014. Disponível em <http://agenciapatriciagalvao.org.br/wp-content/ uploads/2014/12/pesquisaAVON-violencia-jovens versa002-12-2014.pdf>. Acesso em: 15 set. 2017.

IPEA - INSTITUTO DE PESQUISA ECONÔMICA APLICADA. Sistema de Indicadores de Percepção Social: Tolerância social à violência contra mulheres. 2014. Disponivel em: <http://www.ipea.gov.br/portal/index.php?option=com_content\&view=articlecid=244>. Acesso em: 12 mar. 2017.

MELLO, Rodrigo Pontes de. Violência de gênero e educação: nas malhas e tramas discursivas de documentos de domínio público. 2010. 146 p. Dissertação (Mestrado em Psicologia). Universidade Federal de Pernambuco, Recife-PE.

MIRANDA, Cynthia Mara. Violência de gênero nos meios de comunicação: reflexões preliminares e desafios para superação. In: STEVENS, Cristina et al (org.). Mulheres e violências: interseccionalidades. Brasilia-DF: Technopolitik, 2017. E-book. p. 357-366. Disponível em: <https://www.geledes.org.br/wp-content/uploads/2017/03/Mulheres-e-viol\%C3\%AAncias-interseccionalidades.pdf>. Acesso em: out. 2017.

MUSSI, Douglas Miranda; COSTA, Mariana Chaves Fernandes. 0 judiciário brasileiro e a violência de gênero contra a mulher no âmbito das relações familiares. In: I Congresso de Diversidade Sexual e de Gênero, 2014, Belo Horizonte. Anais eletrônicos... Belo Horizonte, 2014. Disponível em < https://anaiscongressodivsex. files.wordpress.com/2015/03/22-mariana-costa.pdf>. Acesso 04 dez. 2016.

OMS - ORGANIZAÇÃO MUNDIAL DA SAÚDE. Prevenção da violência sexual e da violência pelo parceiro ínti- mo contra a mulher: ação e produção de evidência. 2012. 94 p. Disponível em: <http://apps.who.int/iris/ bitstream/10665/44350/3/9789275716359_por.pdf?ua=1>. Acesso em: 10 out. 2016.

ONU MULHERES. \#Elesporelas: Movimento ElesPorElas (HeForShe) de Solidariedade da ONU Mulheres pela Igualdade de Gênero - Visão Geral. [s.d]. Disponível em: <http://www.onumulheres.org.br/wp-content/uploads/2015/03/ElesPorElas_visao_geral.pdfs. Acesso em: 14 mar. 2017.

PASINATO, Wânia (coord.). Diretrizes Nacionais Feminicídio: investigar, processar e julgar com perspectiva de gênero as mortes violentas de mulheres. Braślia: ONU Mulheres, Secretaria de Políticas para Mulheres e Secretaria Nacional de Segurança Pública, abr. 2016. 127 p. Disponível em: <http://www.onumulheres.org. br/wp-content/uploads/2016/04/diretrizes_feminicidio_FINAL.pdfs. Acesso em: 02 jan. 2017.

. Oito anos de lei Maria da Penha. Entre avanços, obstáculos e desafios. Estudos Feministas, Florianópolis, v. 23, n. 2, mai. 2015, p. 533-545.

RODRIGUES, Alexsandro; RAMOS, Hugo Souza Garcia; SILVA, Ronan Barreto Rangel da. Gênero e sexualidade nas escolas: leituras que nos aproximam do campo dos direitos humanos, de alunos e professores. In: RODRIGUES, Alexsandro; BARRETO, Maria Aparecida Santos Corrêa (org). Currículos, gêneros e sexualidades: experiências misturadas e compartilhadas. Vitória: Edufes, 2013. 291 p. Disponível em: < http://repositorio.ufes.br/bitstream/10/821/1/livro\%20edufes $\% 20$ Curr $\%$ C3\%ADculos $\% 2$ C $\% 20 \mathrm{~g} \%$ C3\%AAneros $\% 20$ e\%20sexualidades\%20experi\%OC3\%AAncias\%20misturadas\%20e\%20compartilhadas.pdf>. Acesso em: 15 dez. 2018.

RITT, Caroline Fockink; CAGLIARI, Cláudia Thaís Siqueira; COSTA, Marli Marlene da. Violência contra a mulher compreendida como violência de gênero. Núcleo Interdisciplinar de Estudos sobre Mulher e Gênero da Universidade Federal do Rio Grande do Sul, p. 1-20, 2009. 
SEQUEIRA, Vânia Conselheiro; STELLA, Cláudia. Família e violência: resquícios da cultura patriarcal. Emancipação, Ponta Grossa, v. 12, п. 01, 2012, p. 71-86.

UNESCO - ORGANIZAÇÃO DAS NAÇÕES UNIDAS PARA A EDUCAÇÃO, A CIÊNCIA E A CULTURA; ACNUDH - ALTO COMISSARIADO DAS NAÇÕES UNDIAS PARA OS DIRIETOS HUMANOS. Plano de ação: Programa Mundial para educação em direitos humanos. Primeira etapa. Nova York e Genebra, 2006. 49 p.

Plano de ação: Programa Mundial para educação em direitos humanos. Terceira etapa. Вгаsília, 2015. 31 p.

UNICEF- FUNDO DAS NAÇÕES UNIDAS PARA A INFÂNCIA. Empoderamento de meninas, $\Pi^{0} 2$, abril de 2015. 41 p. Disponivel em: <https://www.unicef.org/ brazil/pt/br_empowergirls02.pdf>. Acesso em: 14 mar. 2017.
VIANNA, Cynthia Semíramis Machado. 0 caso Eloá: análise da abordagem de feminicídio na mídia. In: Fazendo Gênero 9: Diásporas, Diversidades, Deslocamentos, 2010, Florianópolis-SC. Anais eletetrônicos... Disponivel em: <http://www.fazendogenero.ufsc.br/9/resources/anais/1278299010_ARQUIVO_semiramis-eloafeminicidio.pdf>. Acesso em: 13 out. 2017.

WAISELFISZ, Julio Jacobo. Mapa da violência 2012: os novos padrões da violência homicida no Brasil. $1^{\text {a }}$ ed. São Paulo: Instituto Sangari, 2011.

WOJCIECHOWSKI, Paola Bianchi. A fábrica midiática de inimigos e o risco à democracia: Uma análise do papel dos grandes meios de comunicação na elaboração e adoção de leis penais casuísticas no Brasil. Sistema Penal e Violência, Porto Alegre, v. 7, $n^{0}$ 01, jan./jun. 2015, p. 49-65. 


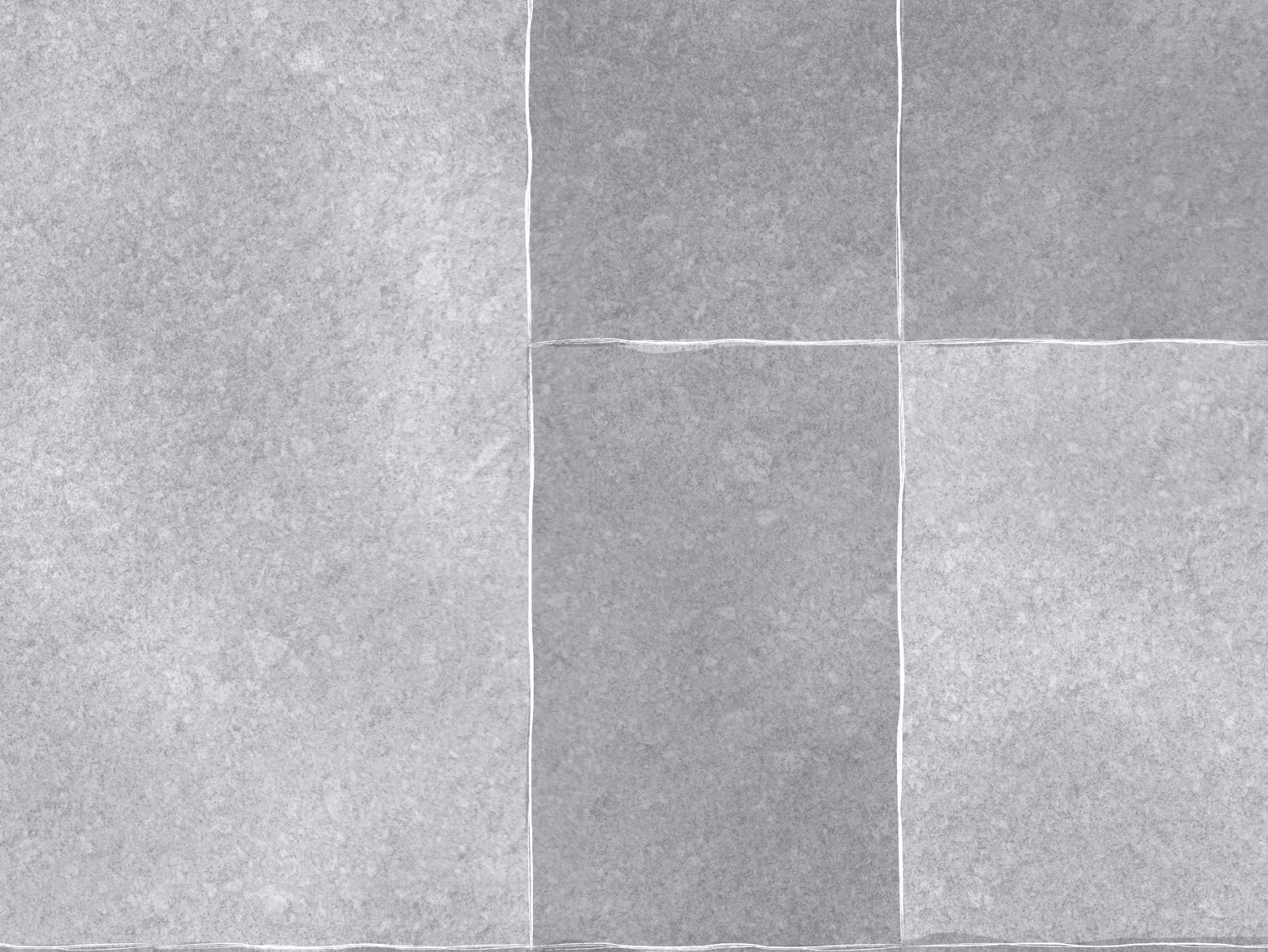

